\title{
EFFET DE L'INGESTION DE PROTÉINES IODÉES SUR LA PONTE ET SUR LA TENEUR EN VITAMINE A DES GEUFS DE POULE
}

PAR

\author{
G. CharLeT-LERY, A. C. FRANgOIS et A. M. LEROY
}

Laboratoire de Recherches Zootechniques de l'Institut National Agronomique

La similitude d'action physiologique des protéines iodées et de la substance thyroïdienne a été mise en évidence dès la fin du $\mathrm{xIx}^{\mathbf{e}}$ siècle. La raison en est dans la présence, à des doses variables suivant le procédé d'ioduration utilisé, de thyroxine dans ces protéines.

D'après les recherches effectuées pour étudier l'influence des protéines iodées sur les volailles, il semble que l'on puisse conclure avec TurNER (5-5 bis), MOORE et REES (4), que l'addition des protéines iodées au régime augmente la quantité d'œufs pondus au cours de l'année en prolongeant surtout la période de ponte pendant l'été (période naturelle de repos thyroïdien). TURNer et Kempster (6), LAw, BIELy et Eilis (3) constatent une amélioration de la ponte des poules adultes au cours de leur deuxième année de ponte et des suivantes. Le poids des animaux ne semble pas être influencé.

L'augmentation du métabolisme chez les animaux recevant des protéines iodées conduit à une augmentation de leurs besoins en vitamines. CoOPER, MARCH et BIELy (I) démontrent l'existence d'une telle augmentation des besoins en vitamine $\mathrm{A}$ en expérimentant avec des poussins en croissance. Nous avons cherché à vérifier s'il existait un effet du même ordre chez les poules pondeuses.

Nous avons utilisé comme source de protéines iodées un produit du commerce, la thyroboline, qui est obtenu par l'ioduration des protéines extraites de la thyroïde. Ce produit a été distribué, conformément aux résultats obtenus par TuRnER, à la dose de $15,5 \mathrm{~g}$ par IOo $\mathrm{kg}$ de nourriture consommée. Son activité physiologique, exprimée en thyroxine, s'élevait à I,4 \%.

Vingt poulettes, âgées de 6 mois au 15 décembre, ont été mises en batterie de ponte non chauffée, et observées pendant trois semaines; elles ont été alors séparées en deux lots identiques quant à leur poids, leur vitesse de croissance depuis la naissance, leur race (Leghorn ou Gatinaise), 
leur état de ponte ou si la ponte n'était pas déclenchée, leurs caractéristiques extérieures de pondeuses (écartement des os pelviens, profondeus de l'abdomen).

Les animaux ont été répartis dans la batterie, de telle sorte qu'aucun des deux lots ne soit favorisé par un meilleur ensoleillement. L'alimentation a été identique : Pâtée complémentaire pour pondeuses à $2 \mathrm{I} \%$ de matières azotées brutes, distribuée à volonté et complétée par $30 \%$ d'avoine germée. Les besoins en vitamines ont été couverts par un apport journalier de $267 \mathrm{U}$. I. de vitamines $\mathrm{D}_{3}$, et I I35 U. I. de vitamines A, soit respectivement 2000 U.I. et 8700 U. I par $\mathrm{kg}$ de nourriture totale consommée.

Nous avons obtenu les résultats suivants :

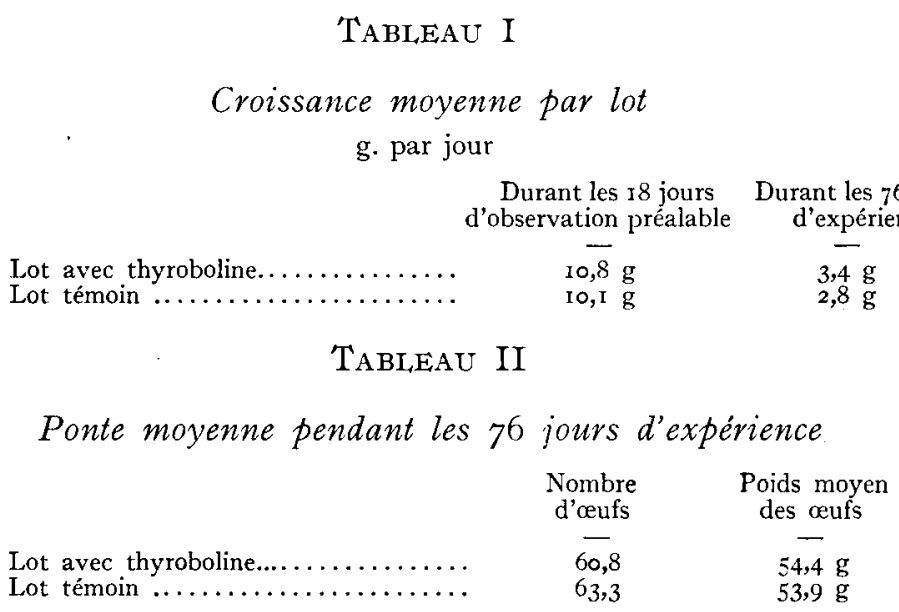

Les différences entre les deux lots ne sont significatives ni pour la croissance, ni pour la ponte.

I,es consommations moyennes n'ont pas montré de différence sensible entre les deux lots.

Les dosages de vitamine $A$ et de carotène effectués en fin d'expérience par la méthode décrite par ailleurs (2) dans le jaune moyen de chacun des lots ont donné les résultats ci-après :

\section{Tableau III}

Teneur en vitamine $A$ et en carotène des aufs

\begin{tabular}{|c|c|c|c|}
\hline & $\begin{array}{l}\text { Poids moyen } \\
\text { des jaunes }\end{array}$ & $\begin{array}{c}\text { Teneur en carotène } \\
\text { en } \gamma \text { par loog } \\
\text { de jaune }\end{array}$ & $\begin{array}{c}\text { Teneur en vitamine A } \\
\text { en } \gamma \text { par roog } \\
\text { de jaune }\end{array}$ \\
\hline & & $\overline{66}$ & 326 \\
\hline & $\mathrm{I} 6, \mathrm{I} \mathrm{g}$ & 104 & 416 \\
\hline
\end{tabular}

L'adjonction de protéines iodées à l'alimentation des poules pondeuses ne modifie pas l'aptitude à la ponte des animaux ni leur engraisse- 
ment. En revanche on constate une moins bonne utilisation du carotène et de la vitamine A. Les œufs des animaux qui reçoivent des protéines iodées sont moins riches en carotène et en vitamine A que les œufs des animaux témoins. On enregistre une chute de $36,5 \%$ du taux de carotène, de $21,5 \%$ du taux de vitamine $A$.

Dans les conditions de notre expérience, l'iodoprotéine utilisée n'a exercé aucune influence sur la ponte; elle a provoqué un abaissement de la teneur des œufs en vitamine $\mathrm{A}$.

\section{BIBLIOGRAPHIE}

(I) Cooper, March, BiEly. - Effet de l'ingestion des thyroprotéines ou de thiouracile sur les besoins en vitamine A du poulet, Endocrinology U. S. A., 46, no 4, p. 404-406, 1950.

(2) Charleti-Lert (G.), Françors (A. C.), Leroy (A. M.). - Influence de la nature du facteur vitaminique $A$ (Axérophtol ou carotène d'huile de palme associé au tocophérol) sur la ponte et les phénomènes de reproduction chez la poule. Ann. Zootechnie, 2, 149, I953.

(3) LAX (G. R.), BIELY (J.), EILIS (H. W.). - Thyroprotein and egg production of pullets. Feedstuffs, p. 34, 22 avril 1950.

(4) Moore (A. C.) and REES (M. G.). - The effect of iodised protein on the laying capacity of hens. Veterin. Journ., 104, p. I56-159, I948.

(5) Turner (C. W.), Irwin (M. R.), REINEKE (E. P.). - Effect of thyroïd hormone on egg production of White Leghorn hens. Poultry Sci., 24, p. I7I-I80, I945.

(5 bis) Turner (C. W.), Kempster (H. L.), Reineke (E. P.). - The effect of thyroprotein on egg production. Poultry Sci., 24, p. 522-523, I945.

(6) TURner (C. W.), KeMpster (H. L.). - Effet de l'incorporation de thyroproteine à la nourriture de poules de 7 ans. Poultry Sci., 28, p. 826-829, I949. 